\title{
Organizational Motivations for Adopting CMMI-based Software Process Improvement: An Extended and Updated Systematic Review
}

\author{
Luiz Sérgio Plácido, Leonardo Araújo, Suzana Sampaio, Marcelo Marinho, \\ Robson Godoi, Alexandre Luna, Fabio Q. B. da Silva \\ Centre for Informatics, Federal University of Pernambuco (UFPE) \\ 50.740-560 - Recife - PE - Brazil \\ \{lsps, lca2, scbs 2 , mlmm, rgam, a jhol, fabio\} @cin.ufpe.br
}

\begin{abstract}
In this paper, we described an update and extension of a systematic review about organizational motivations for adopting CMMI-based Software Process Improvement (SPI). We applied the systematic review method to search, select, evaluate, and synthesize the published research related to this topic. We then compared our findings to those of another systematic review previously published. Our findings showed that the motivations to engaged on CMMI-based SPI changed from being related to software quality to focusing on complying with customers' requirements and satisfaction, as well to conquer external validation.
\end{abstract}

\section{Introduction}

The term Software Process Improvement (SPI) denotes the changes implemented to a software process that brings improvements [Olson et. al. 1989]. The intent of software process improvement is to improve software product quality, to increase productivity, and to reduce product development time [Paulk et. al. 1993]. The Capability Maturity Model Integration (CMMI) is a long-standing, influential, and often-studied approach to SPI, which describes practices and goals for software development process areas, and have frameworks for measuring the compliance of organizations with the goals and practices in these process areas [Chrissis et. al. 2006].

SPI approaches are intended to improve the practice of software engineering and it is, therefore, important understand why organizations decide to adopt existing SPI approaches. This knowledge may help us to develop new or improved SPI approaches whose adoption will better match the objectives of individual organizations. Important research have been conducted about this topic. Some authors have stressed the importance of organizational change in software process improvement programs [Curtis 1997; Humphrey 1997]. Other authors have shown that software organizations usually underestimate the efforts needed to accomplish the change process. [Coffman, Thompson 1997; Goldenson, Herbsleb 1995].

A previous systematic review [Staples et al. 2008] was performed in order to find and analyse the scientific literature presenting the most common reasons and motivations that lead organizations to use CMM and CMMI-based SPI. This previous work analysed the published literature until and including 2004. In this work, we updated and extended this review, focusing exclusively on the use of CMMI. Our goal is to search the literature for answers to the following research question: 


\section{RQ: "Why do organizations embark on CMMI-based SPI initiatives?"}

We performed our review looking for articles published between 2005 and 2010, and added one search engine to the se used by Staples et al. [Staples et al. 2008]. This update and extension was conducted by a group of six students of the post-graduate program at the Centre for Informatics, at Federal University of Pernambuco (UFPE), in Brazil. The project was developed during 2011 and was supervised by the last author.

This article is organized as follows. In Section 2, we present the research method. In Section 3, we describe the results of the review. In Section 4, these results are discussed and compared to the original review. Finally, in Section 5, we present some conclusions and directions for future work.

\section{Research Method}

This section describes each step in the methodology used to carry out this systematic review. We followed the guidelines developed by Kitchenham and Charters [Kitchenham 2007] for systematic reviews. A systematic review protocol was defined based on protocol presented by Staples et al. [Staples et al. 2008].

\subsection{Search environment}

Before start the searches, we decided to create a directory in the cloud. A free web store service was used by all researches to store all artifacts used in and from study, for example electronic versions of publications, generated datasheets, partial reports and others. This enabled a full standardization and control of artifacts by all, because each researcher could access the artifacts as if in a local environment (in self-machine), thought they were remote.

Furthermore, we developed some datasheets to be used in all phases. The datasheets facilitated the organization of data in many aspects, for example a standard to enumerate publications searched, filters to extract objective information, the access of data of reasons by study and publications, and more. The datasheets also enabled the future access of data more precisely, where each phase could depend of other phase.

\subsection{Data Sources and Search Strategy}

Our search process combined automatic and manual search to increase coverage. The search was performed on the list of sources presented in Table 1 using the corresponding search strings. Automatic searches were performed on the entire paper on all engines but Scopus, which does not perform full-text search. For this engine, the search was performed on Title and Abstract. Different search strings were used to address the differences between the sources.

Table 1. Data Sources and Search Strings

\begin{tabular}{|l|l|}
\hline \multicolumn{1}{|c|}{ Resource } & \multicolumn{1}{c|}{ Search Term } \\
\hline Scopus - all sources after 2007 & (CMM OR CMMI) AND "capability maturity" \\
\hline $\begin{array}{l}\text { All Science Direct - all sources after } \\
1989\end{array}$ & (CMM OR CMMI) AND "capability maturity" \\
\hline SpringerLink & (CMM OR CMMI) \\
\hline $\begin{array}{l}\text { Journal of Software Process } \\
\text { Improvement and Practice }\end{array}$ & (CMM OR CMMI) \\
\hline Empirical Software Engineering Journal & (CMM OR CMMI) \\
\hline IEEE Xplore - (IEEE Periodicals) & (CMM <OR> CMMI) <AND> 'capability maturity' \\
\hline IEEE Xplore - (IEEE Conferences) & (CMM <OR> CMMI) <AND> 'capability maturity" \\
\hline ACM Portal & (CMM OR CMMI) AND "capability maturity" -publisher.IEEE \\
\hline $\begin{array}{l}\text { SEI PDF Documents } \\
\text { (searched using Google) }\end{array}$ & $\begin{array}{l}\text { (CMM OR CMMI) AND "capability maturity" } \\
\text {-"people capability" site: sei.cmu.edu filetype:pdf }\end{array}$ \\
\hline
\end{tabular}


Our selection criteria were: papers that contained explicit evidence of specific motivations that a software organization had prior to engage on a CMMI-based SPI. As discussed in Section 4, we did not include papers that only contained statements about possible or actual benefits of CMMI-based SPI. We also excluded those papers that only reported motivations or preferences of individuals or practitioners in the organization for CMMI-based SPI.

We performed pilot tests of all phases of the review to align the understanding among researchers, and to test all search engines. Only IEEE Explore search engine presented problems. One specific search query was defined to this engine to solve this problem. The study only proceeded after all researchers got in an agreement with the results of the pilot tests. Besides, to increase reliability, we performed a search using the same parameter used by [Staples et al. 2008] and achieved consistent results.

In the search phase, the sources (engines) were divided among all researchers. Each researcher was responsible to find and catalogue results from one engine. The search process identified 2405 publications. All papers were catalogued using the Bibtex in a specific datasheet for each engine. An automatic merge was implemented to consolidate all the results and to be able to exclude the duplicated reference. After merging the searches and excluding duplicates, we end up with 1908 articles to start the paper selection phase. The publications were organized in alphabetical order and then distributed to a pair of researchers to minimize bias in selection phases.

\subsection{Paper selection}

The paper selection process has two parts:

- Initial selection: preliminary search selection results that satisfy the selection criteria. This step was based on the analysis of the title and the abstract of the papers;

- Final selection: from the initially selected list of papers, that satisfy the initial selection criteria, a new subset of papers were analysed based on reading the entire paper.

To reduce potential bias, we performed the selection process within pairs or researchers working independently. Each research read the titles and abstracts of each publication of the subset and agreed to select or exclude the publication. Jointly, each researcher pair discussed and reached a final set of selected papers.

\subsection{Study quality assesment}

During the data extraction phase, the quality of each publication was assessed. One researcher performed the quality assessment. Three factors were assessed on a two point (YES or NO) scale:

- Does the publication mention the possibility of selection, publication, or experimenter bias?

- Does the publication mention possible threats to internal validity?

- Does the publication mention possible threats to external validity?

The quality assessment was based on whether the publication explicitly mentioned these issues. We did not make judgements about whether the publication had a "good" 
treatment of these issues. The results of the study quality assessment were not used to exclude publications.

\subsection{Data extraction}

As a pilot test for this phase, we select two papers found by authors in original study and compare the extraction data performed against our extraction data. In the data extraction phase, we extracted information in pairs according to the extraction model shown in Figure 1.

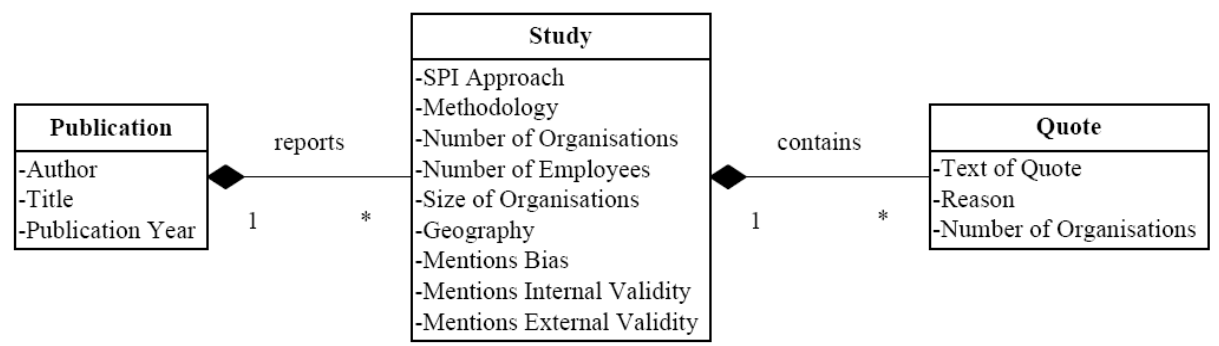

Figure 1. Model for extraction

A Publication is a presentation, technical report, conference article, or journal article. A Study in a Publication described an empirical investigation about software organizations that have reported motivations for their adoption of CMMI-based SPI. A Quote is a piece of text from the Publication presenting the evidence about reasons or motivation for the adoption of CMMI-based SPI.

\subsection{Data synthesis}

At the end of the Data Extraction phase, we had extracted 40 quotes, each containing one or more reasons. Two researchers worked in the synthesis work that consisted in five steps:

1. Generate combinations of quotes and reasons. Excluding the repeated "extracted reason" in the same studies. This resulted in 53 combinations on quotes and reasons;

2. The researchers independently reviewed each quote-reason, in order to create higher-level categories. This work generated an initial list of 35 reasons;

3. Using the initial list of 35 reasons as a starting point, two researchers jointly agreed on a short list of 15 categories of reason to adopt CMMI-based SPI;

4. The researchers independently classified every Quote-reason from the initial list once again into one of the fifteen categories;

5. In other to develop higher-level analyses, the two researchers also agreed on grouping related reason into the 15 categories.

There was a good level of inter-ratter agreement, differences in opinion were discussed in a joint meeting, and it was easily resolved without the need of involving a third researcher.

\section{Results}

This section describes the analyses of the data extracted from our selected studies. Figure 2 shows the results obtained on each stage of our systematic review process. 


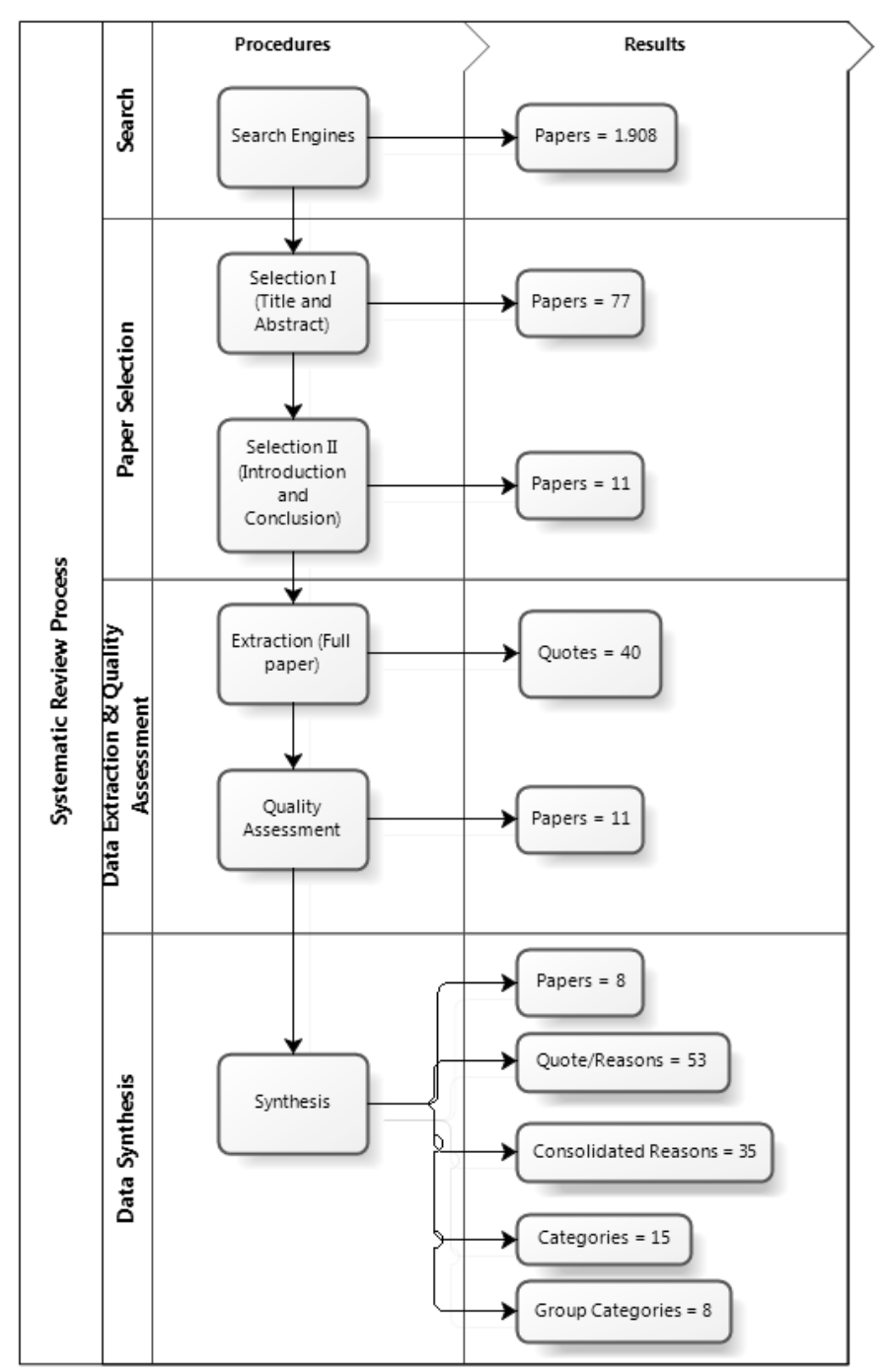

Figure 2. Results obtained on each stage at systematic review process.

\subsection{Data Search}

In the Data Search phase, the searches were conducted in ten sources, the same used in the original work with the addition of the Scopus database. There were two batteries of searches. One proposed to identify the results by source in the same period which the authors performed the original work. The other search was conducted for the period being between and including 2005 and 2010 .

Table 2 shows the amount of items identified during the searches performed on each source. We found a total of 2,197 papers between 2005 and 2010; at least 289 articles were identified and classified as duplicates. The search process was completed with a total of 1908 articles ready for the next selection stage.

Table 2. Results obtained by Engine on Data Search 


\begin{tabular}{|c|c|c|c|c|c|}
\hline Engine & $\begin{array}{c}\text { Team search } \\
\text { until } 2005 \\
\text { (at 13/04/2011) }\end{array}$ & $\begin{array}{c}\text { Between } 2005 \\
\text { and } 2010 \\
\text { (at 09/04/2011) }\end{array}$ & Engine & $\begin{array}{c}\text { Team search } \\
\text { until } 2005 \\
\text { (at 13/04/2011) }\end{array}$ & $\begin{array}{c}\text { Between } 2005 \\
\text { and } 2010 \\
\text { (at 09/04/2011) }\end{array}$ \\
\hline ACM & 155 & 467 & IEEE Journal & 68 & 112 \\
\hline ACM TOSEM & 5 & 3 & JSPI\&P & 81 & 88 \\
\hline ESEJ & 19 & 13 & ScienceDirect & 189 & 240 \\
\hline Google - SEI_PDF & 152 & 66 & Scopus & - & 252 \\
\hline IEEE Conference & 252 & 734 & SpingerLink & 227 & 222 \\
\hline \multirow[t]{4}{*}{ Total } & 583 & 1.283 & & 565 & 914 \\
\hline & & & & Total found & 2.197 \\
\hline & & & & Duplicate & 289 \\
\hline & & & & Total & 1.908 \\
\hline
\end{tabular}

\subsection{Data Selection}

The Data Selection was divided in two phases: Phase 1: Title and Abstract analyses; and, Phase 2: Introduction and the Conclusion analyses. In Phase 1, after reading the Title an Abstract, 77 articles were selected to the next phase. A total of 1.831 papers were eliminated. Among the criteria used, stood out the " 2 - Outside context SPI/CMMI" with $81 \%$, followed by "1 - Outside area or context" with $14 \%$ and " 0 Not applicable" with 5\%. As an example of the second criteria we have [Williams 2008], with the title: "A Practical Application of CMM to medical security capability". It was eliminated because of the following quote from the abstract: "This research Seeks to propose the Practical application, the Capability Maturity Model (CMM) to meet the needs of medical information security practice".

In Phase 2, after reading the Introduction and Conclusion, only 11 articles were selected to the extraction phase. A total of 62 papers were eliminated and 4 papers were not found. Among the criteria used, stood out the "2 - Outside context SPI/CMMI" with $89 \%$, followed by "0 - Not applicable" with $4 \%$, " 4 - Why should organizations embark on CMM-based SPI initiatives?" with 3\% and "5 - What reasons for embarking on CMMI-based SPI are the most important to organizations?" with $2 \%$.

Our review results presented a fairly similar geographic distribution of countries that have implemented the CMMI as a strategy for process improvement as the original review. The United States appeared in first position with 12 articles, followed by Multinational (Representing papers with studies in more than one country) and China with 10, and Australia with 7. Considering the papers evaluated in Phase 2, Figure 3 represents the papers distribution by country. Seven papers out of the 77 evaluated, did not mention the country.

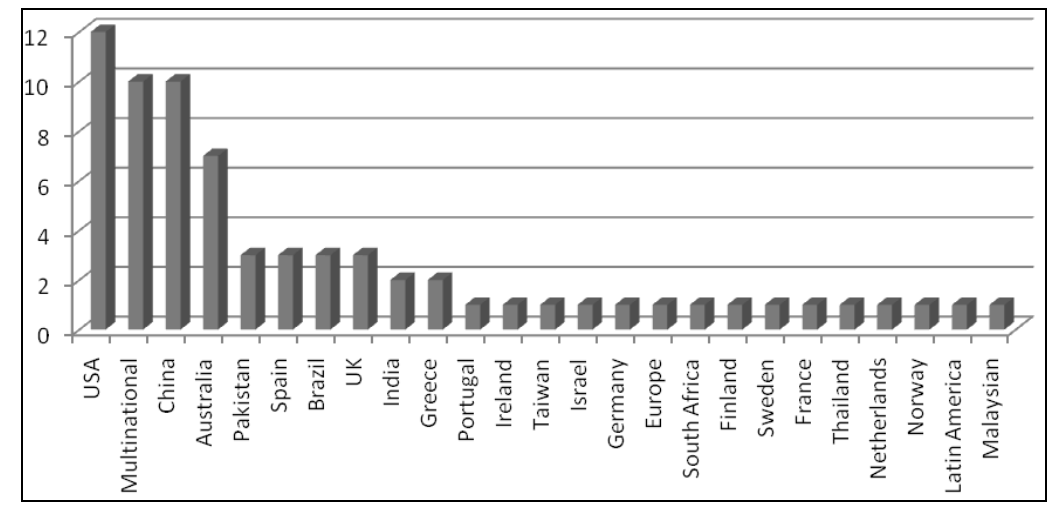

Figure 3. Distribution by country 


\subsection{Data Extraction and Quality Assessment}

In the Data Extraction and Quality Assessment, each research pair read the full paper for the extraction of relevant data. They performed quality assessment along with data extraction. The factor assessed for quality purposes were discussed in Section 2.4.

Data was extracted from 8 Publications, of which 6 were case studies or experience reports about single organizations, one was a survey of 61 organizations and one was an experience report of 9 organizations. Therefore, the studies covered a total of 76 organizations.

From each Study, we extracted a list of Quotes, where each Quote described an initial organizational motivation for the adoption of CMMI-based SPI. Limited paraphrasing was performed, for example to separate single phrases containing lists of multiple separate reasons. We had a total of 40 Quotes extracted from the 8 Studies. The Table 3 shows a summary of all paper in this stage.

Table 3. Papers selected to extract reasons

\begin{tabular}{|l|l|}
\hline \multicolumn{1}{|c|}{ Year } & \multicolumn{1}{c|}{ Paper } \\
\hline 2005 & Software Process Improvement in Small Organizations: A Case Study \\
\hline 2006 & A Survey of CMM/CMMI Implementation in China \\
\hline 2006 & Formalizing Agility, Part 2: How an Agile Organization Embraced the CMMI \\
\hline 2007 & $\begin{array}{l}\text { Information Technology (IT) Industry trends and adaptation of Capability } \\
\text { Maturity Model Integration (CMMI) practices in Pakistan }\end{array}$ \\
\hline 2007 & CMMI in South Africa: Growing international competitiveness \\
\hline 2007 & $\begin{array}{l}\text { Targets, drivers and metrics in software process improvement: Results of a } \\
\text { survey in a multinational organization }\end{array}$ \\
\hline 2008 & $\begin{array}{l}\text { Research and Development of a CMMI-Compliant Requirment Management } \\
\text { System for Software Engineering }\end{array}$ \\
\hline 2010 & Two Case Studies on Small Enterprise Motivation and Readiness for CMMI \\
\hline
\end{tabular}

\subsection{Data Synthesis}

At Data Synthesis phase, 40 quotes were analysed and 53 "sets" of quotes/reasons identified for adoption of CMMI-based SPI. These 53 quotes/reasons were consolidated in 35 reasons. Table 4 shows the 35 reasons suggested during the synthesis.

\section{Table 4. Reason found by synthesis}

\begin{tabular}{|c|c|c|}
\hline \begin{tabular}{l|l}
$\# R$ & Reason \\
\end{tabular} & \begin{tabular}{|l|l|}
$\# R$ & Reason \\
\end{tabular} & \begin{tabular}{|l|l|}
$\# R$ & Reason \\
\end{tabular} \\
\hline 1 Achieve CMM & 13 Improve management visibility & 25 Quality of software \\
\hline 2 Adherence to budget & 14 Improve process & 26 Reduce costs \\
\hline 3 Adherence to schedule & 15 Improve quality & 27 Reduce defects \\
\hline $4 \mathrm{BPO}$ and software development industry & 16 Improve relevant documentation & 28 Reduce lead time \\
\hline 5 Continuous improvement & 17 Marketing & 29 Reduce time \\
\hline 6 Cooperation & 18 Match customer requirements & 30 Reusability \\
\hline 7 Customer required & 19 New contracts & 31 Self need \\
\hline 8 Customers satisfaction & 20 Predictability & 32 Simplify and improve process \\
\hline 9 Employee satisfaction & 21 Productivity & 33 Staff motivation \\
\hline 10 External validation & 22 Profitability & 34 Time effectiveness \\
\hline 11 Government reward & 23 Projects' schedules accurate & 35 Time to market \\
\hline 12 Improve cooperation & 24 Quality & \\
\hline
\end{tabular}

The reasons were organized in 15 categories of reasons. Table 5 presents the 15 categories of reasons that were created to group the first 35 reasons suggested during the extraction phase. Each reason taken from the quotes extracted from the selected studies. 
Table 5. Categories of reasons

\begin{tabular}{|c|c|c|}
\hline $\mathrm{CH}$ & Reasons Categories & Description \\
\hline 1 & $\begin{array}{l}\text { Improve process } \\
\text { continuously }\end{array}$ & $\begin{array}{l}\text { Reasons related to continuous processes improvement, and need for } \\
\text { process management and innovation. }\end{array}$ \\
\hline 2 & Cooperation & Reasons related to staff cooperation and participation in the organization. \\
\hline 3 & $\begin{array}{l}\text { Customer Demand } \\
\text { and Satisfaction }\end{array}$ & Reasons related to attending customer needs and satisfaction. \\
\hline 4 & $\begin{array}{l}\text { Staff motivation and } \\
\text { satisfaction }\end{array}$ & Reasons related to internal employees motivation and satisfaction. \\
\hline 5 & $\begin{array}{l}\text { External validation \& } \\
\text { Marketing } \\
\end{array}$ & $\begin{array}{l}\text { Reasons related to needs of products and services external validation, } \\
\text { marketing, acquisition of new contracts, improved competitiveness and } \\
\text { get into international markets. }\end{array}$ \\
\hline 6 & Government reward & Reasons related to government financial support and encouragement. \\
\hline 7 & $\begin{array}{l}\text { Improve } \\
\text { management visibility }\end{array}$ & $\begin{array}{l}\text { Reasons related to the necessity of improving project management } \\
\text { visibility and the abilities to monitoring the process and project by diverse } \\
\text { levels of management. }\end{array}$ \\
\hline 8 & Predictability & $\begin{array}{l}\text { Reasons related to predictability in process and projects and the ability to } \\
\text { create accurate estimative and schedules. }\end{array}$ \\
\hline 9 & Productivity & Reasons related to improving productivity. \\
\hline 10 & $\begin{array}{l}\text { Improve software } \\
\text { quality }\end{array}$ & $\begin{array}{l}\text { Reasons related to software quality improvement and defect reduction as } \\
\text { well as the need of delivering a compliant product. }\end{array}$ \\
\hline 11 & Reduce time & $\begin{array}{l}\text { Reasons related to reducing the lead time and improving the ability of } \\
\text { performing tasks on schedule in a more efficient and effective way. }\end{array}$ \\
\hline 12 & Time to market & Reasons related to reduced time to market for new products. \\
\hline 13 & Reduce costs & $\begin{array}{l}\text { Reasons related to cost reduction and improving project's adherence to } \\
\text { budget. }\end{array}$ \\
\hline 14 & Profitability & Reasons related to improving profitability in projects execution. \\
\hline 15 & Reusability & Reusability Reasons related in project development. \\
\hline
\end{tabular}

The categories of reasons were synthesized in 8 groups of reasons for adopting of CMMI-based SPI. Table 6 shows the groups and related categories.

Table 6. Groups and Categories

\begin{tabular}{|l|l|}
\hline \multicolumn{1}{|c|}{ Group } & Categories \\
\hline \multirow{4}{*}{ Process } & Improve process continuously \\
\cline { 2 - 2 } & Predictability \\
\cline { 2 - 2 } $\begin{array}{l}\text { Customers \& External } \\
\text { validation }\end{array}$ & Improve management visibility \\
\cline { 2 - 2 } & Externer Demand and Satisfaction \\
\hline \multirow{2}{*}{ Staff } & Cooperation \\
\cline { 2 - 2 } & Staff motivation and satisfaction \\
\hline Government reward & Government reward \\
\hline \multirow{2}{*}{ Product } & Improve software quality \\
\hline \multirow{2}{*}{ iime } & Reduce time \\
\cline { 2 - 2 } & Time to market \\
\hline \multirow{2}{*}{ Costs } & Reduce costs \\
\cline { 2 - 2 } & Profitability \\
\cline { 2 - 2 } & Productivity \\
\hline \multirow{2}{*}{ Reusability } & Reusability \\
\hline
\end{tabular}

Figure 4 shows the distribution of the reasons by groups of reasons. 


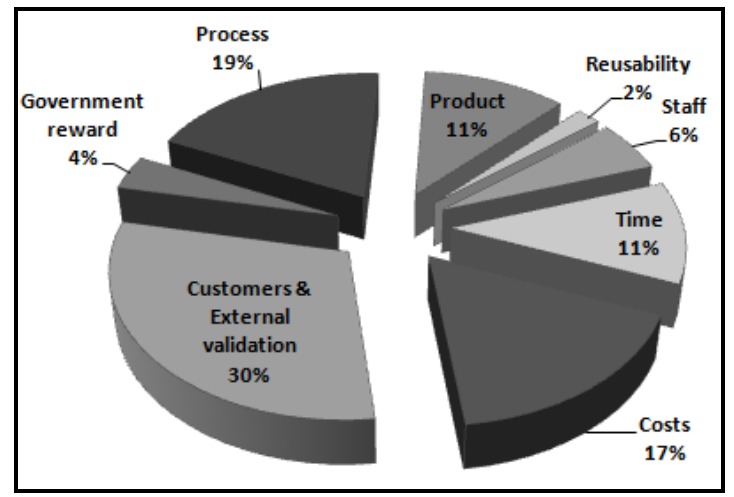

Figure 4 - Reasons by groups

External Customers \& Validation, Process and Costs had the highest number of reasons. Table 7 presents the group of reasons and its geographic distribution.

Table 7. Reasons by Group and Geography

\begin{tabular}{|c|c|c|c|c|c|c|c|c|}
\hline $\begin{array}{l}\text { Reasons by Group and Geography } \\
\text { Group }\end{array}$ & $\begin{array}{l}\text { Geography } \\
\text { Multinational }\end{array}$ & USA & Australia & CHINA & South Africa & Pakistan & Taiwan & Total \\
\hline Costs & 2 & 3 & 2 & & 2 & & & 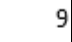 \\
\hline Customers \& External validation & 2 & 5 & 5 & 2 & 1 & & 1 & 16 \\
\hline Government reward & & & & 1 & 1 & & & 2 \\
\hline Process & 2 & 2 & 3 & 2 & & 1 & & 10 \\
\hline Product & 2 & 2 & 1 & & & 1 & & 6 \\
\hline Reusability & 1 & & & & & & & 1 \\
\hline Staff & 3 & & & & & & & 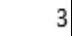 \\
\hline Time & 3 & 2 & 1 & & & & & 6 \\
\hline Total & 15 & 14 & 12 & 5 & 4 & 2 & 1 & 53 \\
\hline
\end{tabular}

Another point observed was that multinational publications have a higher number of reasons (totaling 15), followed by the United States with 14 and Australia with 12 reasons. From the results presented it is interesting to note that China and South Africa are the only groups that fit into the Government reward group of reasons. Another data to be observed is regarding the adoption of the CMMI in Taiwan: despite a strong focus on Government Customers \& reward, Taiwan was also motivated by Process and Product reasons.

\section{Discussion}

This section discusses how the results presented in Section 3 helps on answering our research question presented in the Introduction. We also summarize and discuss the consistency of our findings and the possible bias in our work on motivations for adopting CMMI-based SPI.

\subsection{The systematic review}

All the work performed in the extension allowed the development of results, discussions and conclusions. First of all, it is important to make clear that the systematic review process performed by the original work was followed by the full extension, as suggested by [Kitchenham and Charters 2004]. 
The process used to extend a systematic review followed the same original rules and patterns of the original review. Our review was conducted by six researchers, whereas the original study was conducted by two researchers. In the first round of selection, we found almost twice as much papers in a search period of just five years. Even though a smaller amount of studies were considered in our review, we end up 35 reasons extracted against 21 from the original study.

\subsection{Motivations for Adopting CMMI-based SPI}

The most common group of reasons given by organizations for adopting CMMI-based SPI was "Customers \& External validation" followed by "Process" and "Costs". These three groups combined represents over $66 \%$ of the reasons. The most common group of motivations for adopting CMMI-based SPI identified by [Staples and Niazi 2008] were also observed in our review, such as:

- "Product" reasons that included software quality;

- "Performance" reasons that also included "development time", "development cost", and "productivity";

- "Process" reasons that includes "process visibility", "SPI", and "process measurement";

- "Customer" reasons that includes "customer demands", "market advantage", and "customer satisfaction".

Although all reasons listed above are still motivations that we observed in our review, we have a new most popular reason and a couple of new motivations, not observed before 2005. The original authors concluded that motivations related to software quality were the most popular [Staples and Niazi 2008]. Our study concluded that nowadays the need to attend customers' requirements and satisfaction as well as the need of open the possibilities of new contracts and achieving external validation were the most popular reason for the newer studies. The reasons related to cost reduction; cost-effectiveness, and productivity improvement were then and still are popular reason for adopting CMMI-based SPI.

The new reasons we observed comparing the original systematic review and our extension were:

- "Government reward" that includes government initiatives and government policies to encourage software organizations to acquire CMMI.

- Reason related to "Reusability".

For each study selected for extraction, the research methodologies employed in these studies were analysed. Only three types of metodologies were presented: Surveys, Case Studies and Experience Reports. At least half of the studies analyzed used Case Studies as the research methodology. As the analyses of Bias, the papers did not mention any bias.

\section{Conclusions}

This article presented the result of an extended and updated systematic review. The extended protocol was based on the original results and improvements were made to increase coverage. We presented our results and comparisons with the original review of [Staples et al. 2008]. 
Even though, CMM was originally created to address problems faced by the US Air Force stemming from unreliable delivery of software by its contracted suppliers [8], we observed in our findings that most of the selected studies were performed outside USA and Europe. Nowadays, several papers published about motivation on adopting CMMIbased SPI are spread around the world in places such as Australia, China, Malaysia, South Africa, Taiwan and Pakistan.

One of the strategies on the syntheses phase was to group the categories of reasons. These groups were created to group related reason and motivations that organizations have to adopt CMMI-based SPI. The categories of reasons and its groups were also done by the original systematic review and yet had very little change. The only new categories observed were "Government reward" and "Reusability".

One of the most surprising finding was the fact that organizations worldwide are adopting CMMI-based SPI not for its improvement or software quality, but for getting External validation. This reason was one of the most popular: four out of the eight papers affirm that at least one study has as motivation to adopt CMMI-based on needs of external validation of its products and services. Two other also pointed as motivation reasons related to government financial support and policies for encouragement.

Our broad recommendation is the same as the ones pointed in the extended systematic review [Staples and Niazi 2008]. We recommend that SPI researchers continue to consider the motivations of organizations, and develop SPI approaches that target those organizational motivations. SPI researchers should also accumulate evidence that organizations that adopt SPI approach for specific reasons do in fact achieve the benefits they originally sought.

\section{Acknowledgment}

Fabio Q. B. da Silva holds a research grant from the Brazilian National Research Council $(\mathrm{CNPq})$, process \#314523/2009-0. This article was written while Prof. Fabio Silva was in a sabbatical leave at the University of Toronto, receiving a CAPES research grant process \# 6441/10-6. The authors would like to thank Mark Staples exchanging information that was essential for the development of this work.

\section{References}

Baker, S.W., "Formalizing Agility, Part 2: How an Agile Organization Embraced the CMMI." Agile Conference, 2006.

Calvo-Manzano, J.A. and Cuevas, G. and Mejia, J. and Muoz, MA and San Feliu, T. "How is CMMI-DEV applying when using TSPi project planning." CERMA'09, pp. 143-148, 2009.

Chrissis, M., Konrad, M., Shrum, S. (2006) "CMMI: Guidelines for Process Integration and Product Improvement", 2nd edition, Boston, Addison Wesley.

Coffman, Aaron; Thompson, Kent 1997. Air Force Software Process Improvement Report. Crosstalk - The Journal of Defense Software Engineering, 10, No. 1, 1997

Curtis, Bill 1997. Models of SPI: Getting Beyond Case Studies. In: Proceedings of the Second Annual European Software Engineering Process Group Conference 1997, Amsterdam, C303 1-1 
Dangle, K.C., Larsen, P., Shaw, M., Zelkowitz, M.V., "Software Process Improvement in Small Organizations: A Case Study.” IEEE Software, pp. 68-75, 2005.

Dounos, P. and Bohoris, G., "Factors for Design of CMMI-Based Software Process Improvement Iniciatives" Informatics (PCI), pp. 43-47,2010.

Dwolatzky B., "CMMI in South Africa: Growing international competitiveness." EngineerIT September 2007.

Goldenson, Dennis; Herbsleb, James D. 1995. After the Appraisal: A Systematic Survey of Process Improvement, its Benefits, and Factors that Influence Success. (Technical report CMU/SEI-95-TR-009). Software Engineering Institute, Pittsburgh, PA.

Herbsleb, J.; Carleton, A.; Rozum, J.; Siegel, J.; Zubrow, D. 1994. Benefits of CMMbased software process improvement: Initial results. (Technical report CMU/SEI-94TR-13. ESC-TR-94-013), Software Engineering Institute, Pittsburgh, PA

Humphrey, Watts S. 1997. Managing Technical People - Innovation, Teamwork, and the Software Process. AddisonWesley, Reading, MA.

Justin J. Y. L.,Yung-Sung, L. "Research and Development of a CMMI-Compliant Requirment Management System for Software Engineering.” CSCWD’07 , pp. 7686, 2007.

Khurshid, N. and Bannerman, P. and Staples, M. "Overcoming the First Hurdle: Why Organizations Do Not Adopt CMMI." Trustworthy Software Development Processes, pp. 38-49, 2009.

Khurshid, N., Bannerman, P., Staples, M., "Overcoming the First Hurdle: Why Organizations Do Not Adopt CMMI.” ICSP'09, pp. 38-49, 2009.

Kitchenham, B. and Charters, S. Guidelines for performing systematic literature reviews in software engineering, Technical Report EBSE-2007-01, School of Computer Science and Mathematics, Keele University, 2007.

International Organization for Standardization, ed. 2000. Quality systems. Model for quality assurance in design, development, production, installation and servicing. ISO 9001, International Organization for Standardization, Genev.

Noor, T., Ahmad, D. J., Zafar, D. I., "Information Technology (IT) Industry trends and adaptation of Capability Maturity Model Integration (CMMI) practices in Pakistan." ICIET'07, pp. 1-5, 2007.

Olson, T.; Humphrey, W.; Kitson, D. 1989. Conducting SEI-Assisted Software Process Assessments. Technical Report, CMU/SEI-89-TR-7, Pittsburgh.

Staples, M. and Niazi, M. and Jeffery, R. and Abrahams, A. and Byatt, P. and Murphy, R. "An exploratory study of why organizations do not adopt CMMI." Journal of Systems and Software, pp. 883-895, 2007.

Staples, M. and Niazi, M., "Systematic review of organizational motivations for adopting CMM-based SPI." Information and Software Technology, pp. 605620,2008 .

Staples, M., Niazi, M., "Two Case Studies on Small Enterprise Motivation and Readiness for CMMI.” PROFES'10, 2010. 
Trienekens, J., Kusters, R., van Genuchten, M., Aerts, H. "Targets, drivers and metrics in software process improvement: Results of a survey in a multinational organization.” Journal Software Quality Control, 15, pp. 135-153, 2007.

Williams, P. "A practical application of CMM to medical security capability." Information Management \& Computer Security, pp. 58-73,2008.

Wu, Z., Christensen, D., Li, M., Wang, Q., “A Survey of CMM/CMMI Implementation in China.” SPW'05, pp. 507-520, 2005. 